\title{
SPECIFIC INTERACTIONS BETWEEN LECTINS AND RED BLOOD CELLS OF CHORNOBYL CLEANUP WORKERS AS INDICATOR OF SOME LATE RADIATION EFFECTS
}

\author{
I.S. Karpova \\ Institute of Molecular Biology and Genetics, NAS of Ukraine, Kyiv 03680, Ukraine
}

\begin{abstract}
Aim: Growing interest in lectins is based on their diagnostic and pharmacological potential, especially the ability to inhibit proliferation and initiate apoptosis of cancer cells. In our research microplate lectinoassay able to detect carbohydrate containing structures (receptors) on erythrocyte surface have been proposed for Chornobyl cleanup workers (1986) monitoring. It was expected to reveal specific abnormalities associated with pathological condition arising as a result of late radiation effects. Materials and Methods: Red blood cell (RBC) specimens were taken from 171 persons distributed into the six cohorts: nonexposed donors (1); chronically exposed to the doses below (2) and over $50 \mathrm{cGy}(3)$; exposed to acute radiation without (4) and with manifestation of acute radiation syndrome ( 5 and 6 ). Lectins from 24 species of medicinal plants were purified by ethanol fractionation and electrofocusing. Intensity of lectin-receptor interactions was determined in reaction of hemagglutination. Method of flow cytofluorometry was used to study B-cell counts. Hormone levels in blood serum were determined by radioimmunoassay. Results: An elevated ability of RBC to interact with the panel of lectins was found in all cohorts of exposed persons versus nonexposed donors, moreover, changes in the intensity of lectin-receptor binding depended on the dose of irradiation. Diagnostic value of specific RBC reactions with some individual lectins has been elucidated. Elevated intensity of $\mathrm{RBC}$ reaction with Zea mays lectin was accompanied by a decrease in serum content of thyroid hormones T4 and T3, as well as reduction of B-cell counts. In the case of Rubus caesius lectin the more intensive reaction with RBC, the higher level of hormone cortisol was observed. Conclusions: Deviations from donor's norm in intensity of lectin - RBC interactions in radiation exposed men are supposed to carry information about negative changes in their health status following Chornobyl catastrophe and show the diagnostic potential. The most sensitive reactions have been associated primarily with shifts in endocrine and immune systems. This article is a part of a Special Issue entitled "The Chornobyl Nuclear Accident: Thirty Years After".
\end{abstract}

Key Words: ionizing radiation, Chornobyl cleanup workers, lectins, microplate assay, thyroid hormones.

Lectins are known as universally occurring sugarbinding proteins of non-immune origin that agglutinate cells and precipitate polysaccharides or glycoproteins [1]. These biologically active compounds can specifically recognize carbohydrate residues (receptors) exposed on cellular membranes in all types of living cells. It should be emphasized that membranes of erythrocytes are particularly saturated with such residues, so reaction of hemagglutination is routinely employed for lectins detection and research. Lectins provide a communicative process between molecules, cells and their environment based on specific proteincarbohydrate non-covalently interactions.

Growing fundamental interest in lectins is due to the concept of glycocode, according to which carbohydrates are capable of transferring substantial biological information, and lectins can decipher this information [2]. Human endogenic lectins demonstrate a wide range of physiological activities: they play role in fertilization, modulation of immune response by activation of $B$ - and T-lymphocytes and neutrophils, mediate leukocyte adhesion and migration, activation of complement system and phagocytosis. Some endogenic lectins have anti-viral and anti-bacterial activity,

Submitted: September 07, 2016.

Correspondence: E-mail: i.s.karpova@imbg.org.ua; karpova_is@mail.ru Abbreviations used: ARS - acute radiation syndrome; GAA - hemagglutinating activity; IN - integral index; MBL - mannose binding lectin; NRCRM - National Research Center for Radiation Medicine; RBC - red blood cells; T3 - triiodothyronine; T4- thyroxine. interact with hormone and cytokine receptors, are involved in apoptosis and process of metastasis etc. [1].

Plant (exogenic) lectins have been used as tools in biochemistry and histochemistry for the characterization of changes on the human membrane surfaces accompanying physiological and pathological conditions, cancer associated differences being of grate importance.

The paradox lies in the fact that in different techniques based on diagnostic capabilities of plant lectins just red blood cells (RBC) were out of view of researchers. A priori very high receptor density for different lectins on the surfaces of RBC as circulating and relatively long-living cells indicates an important physiological role of these structures not yet entirely clarified. It was assumed and supported by several papers that besides the main function to transport gases erythrocytes are able to deposit and transport hormones, some nutrients and chemotherapeutic agents $[3,4]$. Also the function of erythrocytes is elimination of undesirable particles including bacteria and circulating immune complexes via receptor CR1. This erythrocyte receptor was shown to mediate immune adherence under control of serum endogenic lectin $\mathrm{MBL}$ (mannose binding lectin) demonstrating that RBC are involved in an immune function [5].

Based on the work $[6,7]$, Ukrainian scientists have proposed peripheral blood erythrocytes as a model for diagnostics of malignant diseases using a panel of 24 lectins isolated from medicinal plants (patent of Ukraine № 3060 from 26.12.94). In- 
terest to lectins from medicinal plants was motivated by an assumption of their putative pharmacological significance [7] which remains relevant to our time with accent on lectins' ability to initiate apoptosis of cancer cells, in particular, to inhibit proliferation of leukemia cells [8, 9].

In our research erythrocytes as a test system have been used in analogic lectinoassay with some modifications and data processing. In this paper, we present a review of the main results obtained in collaboration with Dr. E.V. Mikhailovskaya and Dr. I.G. Khalyavka (National Research Center for Radiation Medicine NRCRM) concerning the clinical monitoring of cleanup workers (named liquidators) subjected to various doses of irradiation as result of Chornobyl accident.

The aim was to investigate the specific deviations in intensity of hemagglutination using $\mathrm{RBC}$ of radiation exposed men and the panel of lectins isolated from medicinal plants in order to estimate their diagnostic significance by assessment of associations with known parameters of immune and endocrine status.

\section{MATERIALS AND METHODS}

Panel of 24 lectins used in proposed assay was obtained from the following medicinal plants: Achillea millefolium, Alnus glutinosa, Batula alba, Calendula officinalis, Diospyros kaki, Equisetum arvense, Eucaliptus globulus, Fragaria vesca, Glechoma hederacea, Gnaphallum uliginosum, Grataegus monogyna, Hypericum perforatum, Leonurus cardiaca, Mentha piperita, Menyanthes trifollata, Plantago major, Polygonum aviculare, Polygonum bistorta, Rubus caesius, Salvia officinalis, Sambucus nigra, Tussilago farfara, Urtica dioica, Zea mays. Plant selection was motivated by their use in herbal medicine as antitumor substancies.

Purification of lectins from dried material was performed by ethanol precipitation of crude extracts to $50 \%$ saturation combined with a modified method of isoelectric focusing [10]. Preparations were dried by lyophilization and stored at $-20{ }^{\circ} \mathrm{C}$. Before use partly purified lectins were dissolved in saline to the final concentration of $1 \mathrm{mg} / \mathrm{ml}$. Microplates with diluted lectins were dried and can be stored in solid state at $-4{ }^{\circ} \mathrm{C}$ for 2 weeks without loss of lectin activity. Hemagglutinating activity (GAA) of lectins was estimated visually by adding $2 \%$ suspension of native human erythrocytes in buffered saline, $\mathrm{pH} 7.4$, to serial two fold dilutions in sterile 96-well polystyrene microplates with U-like bottom. It was presented as numbers (relative units) reflecting diameter of erythrocytes pellet where 1 unit was equivalent to a diameter of $1 \mathrm{~mm}, 2$ units $-2 \mathrm{~mm}$ and 3 units $3 \mathrm{~mm}$, respectively. Intensity of GAA (designated as $\mathrm{N}$ ) was calculated for each lectin by summing the values in relative units along the entire order of wells up to the last lectin dilution where hemagglutination was observed. To represent the integral result of the lectins - erythrocyte interactions the sum of $\mathrm{N}$ values for all lectins tested have been calculated and desig- nated as IN - integral index of the microplate assay. Lectin carbohydrate specificity was tested by ability of 20 sugars to inhibit GAA.

Blood samples were taken from men exposed in 1986 and being monitored in NRCRM from 1990 to 1996, who were attributed to different cohorts depending on the character and dose of exposition: non-exposed donors served as the control (cohort 1); liquidators chronically exposed to doses below (cohort 2) or higher (cohort 3) 50 cGy; persons exposed to acute radiation with subclinical form of acute radiation syndrome (ARS) (cohort 4); persons who suffered from ARS with biologically estimated doses below (cohort 5) and over (cohort 6) 200 cGy.

To find associations, the results of the microplate assay were compared with the data of standard clinical tests. To study main subtypes of white blood cells method of flow cytofluorometry was used (flow cytometer Becton Dickinson, USA). Hormone levels were determined in blood serum of patients using radioimmunoassay kits (CIS, France).

Statistical analysis was performed using Origin 8.1 program (OriginLab Corporation). Standard statistical descriptions of parameters were used to characterize the data. The Student's $t$-criterion was used to parametric data analysis and White's test to nonparametric estimation [11]. Results with $p<0.05$ were considered significant. Data are presented as the mean and the error bars represent experimental standard error ( \pm standard deviation, SD).

\section{RESULTS AND DISCUSSION}

Proposed microplate lectinoassay actually represents blood test for non-traditional parameters, namely availability and accessibility of carbohydrate containing structures (receptors) on RBC surface able to interact with lectins from 24 species of medicinal plants. Previously it has been shown that in the case of tumors ability of lectins to interact with RBC is reduced by $30-60 \%$, some types of reactions being entirely absent (Patent of Ukraine № 3060 from 26.12.94). In our work this microplate assay with lectins from medicinal plants was first applied for the studies of late effects of radiation.

Altogether there were examined 171 persons distributed into the 6 cohorts (Table 1). The control group (cohort 1) consisted of non-irradiated young healthy men - cadets of Special Police Subdivision not involved in Chornobyl zone actions. The cohort 2 also consisted of young healthy men registered in the Registry of Ministry of Internal Affairs who during road traffic patrol in the Chornobyl $30 \mathrm{~km}$ zone were chronically exposed to the doses below 50 cGy (average dose of $16.0 \mathrm{cGy}$ ). Cohorts 3-6 consisted mainly of middle-aged men varied by the character of work carried out at the moment of their participation in the liquidation of consequences of Chornobyl accident 1986 . These persons obtained relatively high doses of continuous (cohort 3) or acute (cohorts 4-6) radiation that varied from 56.4 to 270 cGy. It was just 
Table 1. Cohort characterization by age and profession at the moment of cleanup operations in 1986

\begin{tabular}{|c|c|c|c|c|c|c|}
\hline Cohorts & 1 & 2 & 3 & 4 & 5 & 6 \\
\hline $\begin{array}{l}\text { Number } \\
\text { Age }\end{array}$ & $\begin{array}{c}26 \\
21.7 \pm 0.6\end{array}$ & $\begin{array}{c}74 \\
31.0 \pm 0.8\end{array}$ & $\begin{array}{c}23 \\
39.6 \pm 2.4\end{array}$ & $\begin{array}{c}20 \\
36.6 \pm 1.5\end{array}$ & $\begin{array}{c}11 \\
377 \pm 35\end{array}$ & $\begin{array}{c}17 \\
396 \pm 23\end{array}$ \\
\hline Cadets of Special Police Subdivision & + & - & - & $\begin{array}{c}0.0-1.0 \\
-\end{array}$ & $\begin{array}{c}01.1-0.0 \\
-\end{array}$ & $\begin{array}{c}0.0-2.0 \\
-\end{array}$ \\
\hline Road patrol & - & + & - & - & - & - \\
\hline Nuclear power station staff & - & - & + & + & + & + \\
\hline Firefighters & - & - & - & + & + & + \\
\hline Builders & - & - & + & + & + & + \\
\hline Military security & - & - & + & + & + & + \\
\hline $\begin{array}{l}\text { Dose, cGy by radiation dosimeter } \\
\text { by cytogenetic method }\end{array}$ & - & $16.0 \pm 11.1$ & $84.7 \pm 12.2$ & $56.4 \pm 8.3$ & $85.5 \pm 19.9$ & $270 \pm 33.3$ \\
\hline
\end{tabular}

in these cohorts the high levels of negative radiation effects would be expected.

It was found in our lectinoassay studies that everyone tested has an individual pattern of RBC response to the panel of lectins. So, an integral index of the microplate assay (IN) summarized for all cohort members reflects the principal trend that characterizes the state of the erythrocyte membrane receptors in exposed men, regardless of the individual fluctuations. The mean values of the IN for each cohort versus average dose are given in Fig. 1. It is clear that in all cohorts of exposed men value of the IN characterizing the intensity of the reaction of RBC with a set of lectins significantly exceeds the level of control ( $\mathrm{IN}=$ $215.6 \pm 4.1$ relative units). Reliable were also deviations of IN mean values for patients in cohorts 3-6 who received higher doses of radiation compared with cohort 2 exposed to low doses ( $I N=240.3 \pm 3.8$ ). Also it should be noted that IN values for persons exposed to acute irradiation were higher than in case of high doses of continuous exposition (cohort 3 ). In cohorts 4-6 with subclinical form (cohort 4) and clinical symptoms of ARS integral lectinoassay index reaches the upper limit for this panel of lectins (IN $=280.0 \pm 10.3$ ) and no longer depends on the dose increasing. Within each of the selected cohorts, individual dose dependence of IN was not observed. This may be the result of differences in individual resistance to radiation when the same dose causes a different response. Nor can we exclude the possibility of some errors in determination of individual radiation dose using a radiometer. Proper exposure doses could be higher, than officially declared.

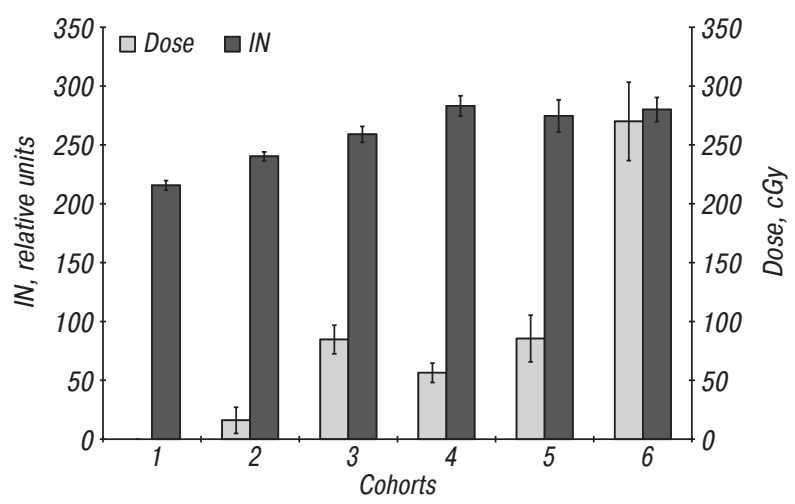

Fig. 1. The intensity of interactions between RBC and a set of lectins as mean values of IN in relation to mean exposure doses for all cohorts tested: 1 - unexposed donors $(n=26)$; continuous exposition: $2-<50$ cGy $(n=74) ; 3->50$ cGy $(n=23)$; acute exposition: $4-<100$ cGy $(n=20) ; 5->100$ cGy $(n=11$, ARS I); $6->200$ cGy $(n=17$, ARS II, ARS III)
Thus, the IN demonstrate association with average cohort dose $(r=0.64)$ and the character of exposure (continuous, acute). In situation with small and middose chronic exposure the intensity of the reaction with lectins exhibits a linear dependence on the average cohort dose. But in the case of acute exposure IN value reaches a plateau and no longer detects a connection with the dose. Obviously if the structural and functional changes have affected almost all available receptors for a given panel of lectins, a further increase in the intensity of the reaction does not occur. These results suggest that in either case, IN can be considered as an indicator of erythrocyte receptors condition in exposed men.

As shown in Table 2, distribution of personal IN variation in the most contrasting cohorts showed directed divergence from monomodal distribution (unexposed control) to bimodal one in the case of continuously exposed to low doses and almost flat without the expressed peak for joint group of persons (cohorts 5 and 6 ) with clinical symptoms of ARS. So, one or more discrete subgroups representatives of which have enhanced GAA intensity in microplate lectinoassay have been formed after exposition. Especially clear these deviations have been manifested in patients who suffered from ARS, where persons with normal IN values are virtually absent.

Table 2. Distribution of liquidators from different cohorts by personal values of the IN reflecting intensity of their red-cells interactions with set of lectins

\begin{tabular}{lcccccc}
\hline & \multicolumn{4}{c}{ Cohorts } \\
\cline { 2 - 7 } IN classes, relative units & $\begin{array}{c}\text { Unexposed } \\
\text { donors }\end{array}$ & $\begin{array}{c}\text { Continuous } \\
\text { exposition } \\
<50 \text { cGy }\end{array}$ & $\begin{array}{c}\text { Acute } \\
\text { exposition } \\
>100 \text { cGy } \\
\text { (ARS I, II, III) }\end{array}$ \\
\cline { 2 - 7 } & $\mathrm{N}$ & $\%$ & $\mathrm{~N}$ & $\%$ & $\mathrm{~N}$ & $\%$ \\
\hline$\leqslant 189$ & 1 & 3.85 & 2 & 2.70 & 1 & 3.57 \\
$190-209$ & 4 & 15.38 & 11 & 14.86 & 2 & 7.14 \\
$210-229$ & 12 & 46.15 & 10 & 13.51 & 3 & 10.71 \\
$230-249$ & 6 & 23.08 & 11 & 14.86 & 6 & 21.43 \\
$250-269$ & 3 & 11.54 & 13 & 17.57 & 4 & 14.29 \\
$270-289$ & 0 & 0 & 20 & 27.03 & 3 & 10.71 \\
$290-309$ & 0 & 0 & 7 & 9.46 & 4 & 14.29 \\
$310-329$ & 0 & 0 & 0 & 0 & 4 & 14.29 \\
$\geqslant 330$ & 0 & 0 & 0 & 0 & 1 & 3.57 \\
Number of persons tested & 26 & & 74 & & 28 & \\
\hline
\end{tabular}

It should be noted that cohort 2 with persons exposed to low doses was quite homogeneous by age and profession and its representatives being first examined had no complaints and chronic diseases. After their participation in rescue operations in 1986 and being followed in NRCRM they got complaints about health concerning first of all arterial hypertension, 
symptoms of coronary heart disease and neurologic symptoms. It seems evident that reduction in proportion of persons with normal reaction of RBC with lectins (Table 2) reflects the trend for the worsening in their health. The most important biological systems responsible for homeostasis of human body, especially hematopoietic (hematopoietic stem cells), immune, and neuroendocrine are known to be very sensitive to ionizing radiation [12]. So, pronounced deviations above the normal IN values for persons suffering from ARS may result from the heterogeneity of chronic diseases affecting all the vital organs and systems in this group: hemopoietic diseases, endocrine system pathology, dysfunction of the immune system, diseases of cardiovascular, genitourinary, central nervous system, diseases of digestive organs, etc [13]. Also ionizing radiation was shown to induce stress of antioxidative system and activate the processes of lipid peroxidation that may result in damaging the RBC membrane.

The revealed intensification in interactions of RBC and lectins may also result from structural modifications in the composition of glycoconjugates covering the erythrocyte membrane accompanying pathological changes in various organs and systems of the irradiated body which were more pronounced in patients who have received a higher dose. The development of many diseases is accompanied by abnormal glycosylation of soluble and receptor proteins [14].

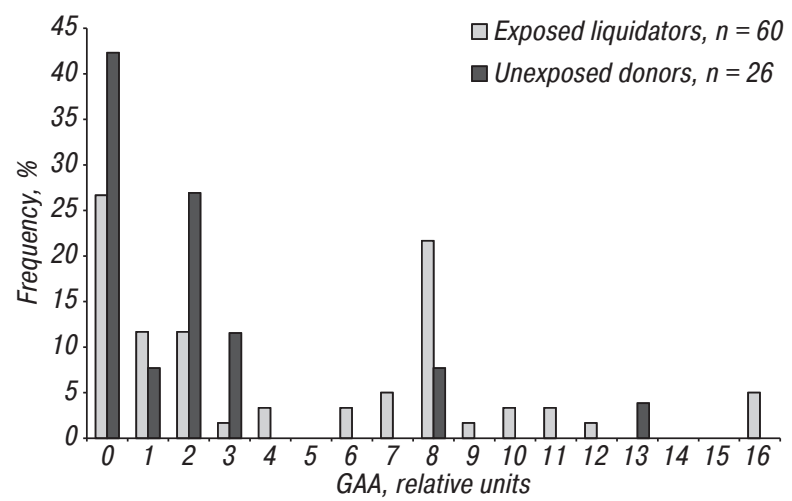

Fig. 2. Distribution of exposed persons depending on the intensity of RBC interaction with Zea mays lectin. ${ }^{*} p<0.05$ compared to unexposed donors

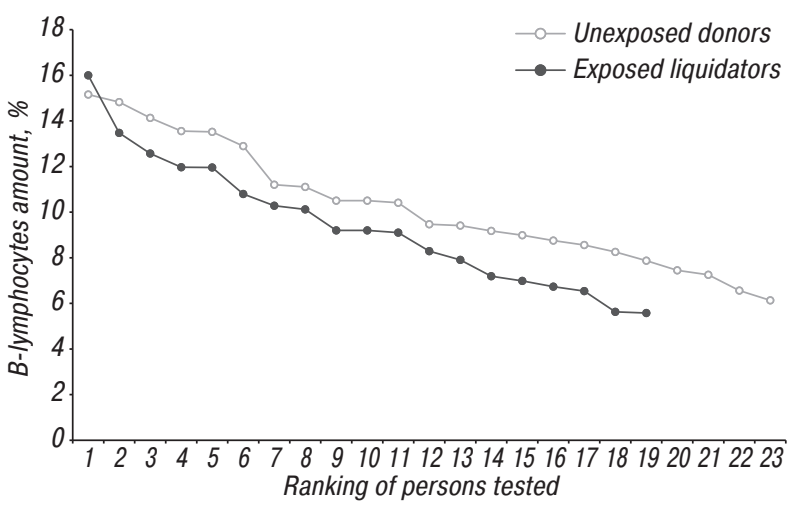

Fig. 3. Distribution of exposed persons with elevated intensity of RBC and Zea mays lectin interaction depending on B cell counts in peripheral blood. ${ }^{*} \mathrm{p}<0.05$ compared to unexposed donors
Changes in the intensity of lectin - receptor binding accompanying the deterioration of the health of liquidators show the diagnostic potential of such reactions. But results obtained required further decifering by comparing the lectinoassay data with data of standard clinical examinations.

For this purpose the search of specific unidirectional deviations in the reaction with individual lectins for exposed men versus unexposed donors was carried out. An example of such analysis is given in Fig. 2 for persons continuously exposed to low doses (cohort 2). Over 30\% representatives of this cohort demonstrated high RBC reactivity with lectin of Zea mays pestils. This lectin with specificity to galactose and $\mathrm{N}$-acetylgalactosamine was found to agglutinate the rabbit erythrocytes. As it is evident from the data presented in Fig. 2, Zea mays lectin really interacts very weakly with erythrocytes of the majority of healthy unexposed donors.

It was shown that persons who had the elevated reactivity of their RBC with Zea mays lectin demonstrated the parallel reduction of $B$-cell (CD19) counts in blood serum (Fig. 3).

This and some other unidirectional deviations in the reaction with individual lectins were more precisely identified in persons exposed to high doses of acute radiation for whom the widest possible range of tests was carried out.

From data presented in Table 3 it is evident that persons demonstrating elevated reactivity of their RBC with Zea mays lectin have significantly lower serum content of thyroid hormones - thyroxine (T4) and triiodothyronine (T3), the T4 content being below the lower limit of normal level $(69 \mathrm{nmol} / \mathrm{l})$. Consequently the intensive reaction with Zea mays lectin may indicate a decrease in thyroid gland function. Our data are in agreement with published works where valid immunological and hormonal shifts were noted in health status of liquidators and domination of thyroid diseases was generally accepted.

Table 3. Hormone level in blood serum of liquidators subjected to acute irradiation and characterized by normal (A) and elevated (B) intensity of hemagglutination in reaction with individual lectins

\begin{tabular}{|c|c|c|c|c|}
\hline \multirow{3}{*}{ Hormones } & \multicolumn{4}{|c|}{ Lectins } \\
\hline & \multicolumn{2}{|c|}{ Zea mays } & \multicolumn{2}{|c|}{ Rubus caesius } \\
\hline & $\bar{A}$ & $B$ & $A$ & B \\
\hline$\overline{\mathrm{T} 4, \mathrm{nmol} / \mathrm{l}}$ & $91.5 \pm 4.9$ & $60.2 \pm 9.5^{\star}$ & $87.2 \pm 6.1$ & $84.7 \pm 7.0$ \\
\hline $\mathrm{F} \mathrm{T4}, \mathrm{pmol} / \mathrm{l}$ & $13.0 \pm 0.4$ & $12.7 \pm 0.5$ & $12.9 \pm 0.4$ & $12.9 \pm 0.5$ \\
\hline $\mathrm{T} 3, \mathrm{ng} / \mathrm{ml}$ & $1.55 \pm 0.08$ & $1.26 \pm 0.08$ * & $1.34 \pm 0.07$ & $1.65 \pm 0.09 *$ \\
\hline Cortisol, nmol/l & $478.4 \pm 22.0$ & $433.1 \pm 38.4$ & $435.2 \pm 20.3$ & $526.2 \pm 27.7^{*}$ \\
\hline $\mathrm{n}$ & 29 & 19 & 25 & 23 \\
\hline
\end{tabular}

Note: The difference is significant ${ }^{\star} p<0.05$ compared to $A$.

Second example presented in Table 3 shows a positive correlation between elevated GAA of RBC with Rubus caesius lectin and higher level of hormone cortisol which is produced by adrenal glands. Among the factors increasing cortisol levels the leading role belongs to stressful situations. Many researchers note that increase of non-cancer pathology in late period after Chornobyl accident is the result of combined effect of ionizing radiation and a complex 
of non-radiation stressful factors (psychological, social etc) [13].

Thus, deviations in the reactions of erythrocytes with Zea mays and Rubus caesius lectins can serve as indicators of endocrine status changes which in latent period are difficult to diagnose. Special RBC sensitivity to the changes of thyroid status can be attributed to their participation in the transport of thyroid hormones $[15,16]$. The change of thyroid status may in turn affect parameters of oxidative stress [17] which can cause changes of membrane condition.

Specific variations in reactions with the individual lectins have been identified for each studied cohort and an increase in the number and intensity of such abnormalities observed in persons who obtained higher doses of ionizing radiation [18].

We can assume that the increase in the intensity of the interaction of lectins with erythrocyte receptors of exposed men indicates the strengthening of adaptive reactions of the organism in response to changes in blood levels of biologically active substances.

We know that in normal condition functions only a small part of the cell membrane receptors and their number may increase with a decrease in the level of certain metabolites [19].

It should be noted that the vector in reaction of hemagglutination with the set of lectins towards increased values in exposed individuals is opposite to that observed by previous researchers in cancer patients with significantly lower values of IN integral index. Decrease in intensity of the reaction can occur in response to the appearance of toxic metabolites or increased content of biologically active substances (such as cytokines) due to the induction of expression of certain genes [20]. Radiation-induced tumors are a rare stochastic events and can occur in more distant terms in comparison with the interval in which our research was conducted [21].

The results obtained and the published data leads to the conclusion that a set of lectins in reaction with erythrocyte receptors can be used as a tool to obtain information about the changes of main organs and systems affected by exposure to ionizing radiation manifested at late period. Deviations from donor's norm in lectin - erythrocyte ineractions in radiation exposed men are supposed to be early indicators of negative changes in their health status following Chornobyl catastrophe. The most common primarily changes were shown to be associated with the shifts in endocrine and immune systems. Health problems initiated by Chornobyl accident are not in the past. Now descendants of liquidators are coming into reproductive age. Therefore, after some modernization the sensitive test with lectins may be useful for screenshot survey and formation of high-risk groups. The complex mechanisms underlying changes in the erythrocyte cell surface which are related to pathology development, and a putative contribution of endogenous lectins is a field for further investigations.

\section{ACKNOWLEDGEMENTS}

This work was supported by grants provided by the National Academy of Sciences of Ukraine "Application of lectins of medicinal plants as new diagnostic tools and anticarcinogenic agents" (program "Chornobyl II", code 4.7.3); "Lectins of medicinal plants as a tool of early diagnosis and prevention of negative changes in human health appeared as a result of effects of the Chornobyl accident" (project code 7.17.4141).

\section{REFERENCES}

1. Sharon N, Lis H. Lectins. New York: Springer, 2007. $472 \mathrm{p}$.

2. The Sugar Code. Fundamentals of Glycosciences. HJ Gabius, Ed. Weinheim: Wiley-VCH, 2009. 569 p.

3. Kuipers S, Harmsen T, van Dijk H. Erythrocyte-mediated transport and elimination. In: The ancient complement system: role in physiology and defense. Enschedethe Netherlands: Febodruk BV, 2003: 74-8.

4. Garipova MI, Bashkatov SA, Dazko OI, et al. Two different hormone transporting systems in human blood: features of peptide hormone transport in human blood. J Biomol Struct Dyn 2015; 33 (Suppl 1): 104-4.

5. Eddie WK, Takahashi K, Ezekowitz RA, et al. Mannosebinding lectin and innate immunity. Immunol Rev 2009; 230: 9-21.

6. Koch B, Regnat W, Schedel I, et al. The binding of different lectins on peripheral blood mononuclear cells from patients with chronic inflammatory and malignant diseases. Immunobiol 1983; 164: 99-109.

7. Golynskaya EL, Pogorelaya NF, Makarenko VI. Lectins as a possible pharmacologically active ingredients in some medicinal plants. In: The Study and the Use of Lectins. Lectins in Biology and Medicine, Part 2. Tartu: Sci notes Univ of Tartu, 1989: 212-17 (in Russian).

8. Hamid R, Masool A, Wani IH, et al. Lectins: proteins with diverse applications. J Applied Pharm Sci 2013; 3: $93-1$.

9. Yau T, Dan X, Wing Ng CC, et al. Lectins with potential for anti-cancer therapy. Molecules 2015; 20: 3791-810.

10. Sova O. Autofocusing - a method for isoelectric focusing without carrier ampholytes. J Chromatography 1985; 320: $15-22$.

11. Mintzer OP, Ugarov BN, Vlasov VV. Methods of medical information processing. Kiev: Vishcha Shkola, 1991. 272 p. (in Russian).

12. Shao L, Luo Y, Yi D. Hematopoietic stem cell injury induced by ionizing radiation. Antioxid Redox Signal, 2014; 20: $1447-62$.

13. Kirkbride KC, Ray BN, Blobe GC. Cell-surface coreceptors: emerging roles in signaling and human disease. Trends Biochem Sci 2005; 30: 611-21.

14. Schindhelm RK, ten Boekel E, Heima NE, et al. Thyroid hormones and erythrocyte indices in a cohort of euthyroid older subjects. Eur J Intern Med 2013; 24: 241-4.

15. Dolomatov SI, Pishak VP, Slipenyuk TS, et al. Erythrocyte abilities to deposite the thyroid hormones: regulatory role of physico-chemical factors in vitro. Vopr Med Chimii 1998; 44: 380-3 (in Russian).

16. Erdamar H, Demirci H, Yaman H, et al. The effect of hypothyroidism, hyperthyroidism, and their treatment on parameters of oxidative stress and antioxidant status. Clin Chem Lab Med 2008; 46: 1004-10. 
17. Karpova IS, Koretskaya NV. Dependence of the receptorlectin interaction on radiation mode and dose in Chornobyl accident liquidators. Biopolym Cell 2003; 19: 133-9 (in Russian).

18. Teppermen J, Teppermen H. Physiology of metabolism and the endocrine system. Moscow: Mir, 1989. $656 \mathrm{p}$. (in Russian).

19. Grodzinsky DM. Radiobiology. Kyiv: Lybid, 2001. 448 p (in Ukrainian).
20. Gluzman DF, Sklyarenko LM, Zavelevich MP, et al. Overview on association of different types of leukemias with radiation exposure. Exp Oncol 2015; 37: 89-93.

21. 30 years after Chernobyl: pathogenetic mechanisms of somatic diseases formation, experience of medical support of liquidators of Chernobyl nuclear power plant accident consequences: a monograph. SS Alexanin, ed. St. Petersburg: Politehnica-print, 2016. 506 p. (in Russian). 